\title{
Test-retest reliability of tip, key, and palmar pinch force sense in healthy adults
}

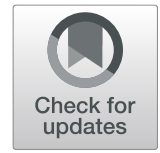

\author{
Lin $\mathrm{Li}^{1}$, Yanxia $\mathrm{Li}^{2^{*}} \mathrm{D}$, Changhong $\mathrm{Wu}^{2}$ and Xinyan Zhang ${ }^{3}$
}

\begin{abstract}
Background: No previous studies have investigated the test-retest reliability of tip, key, and palmar pinch force sense in healthy adults. The present study explores the test-retest reliability of tip, key, and palmar pinch force sense for different force levels in healthy adults during an ipsilateral force reproduction task.

Methods: Fifty-six healthy subjects were instructed to produce varying levels of reference forces (10, 30, and 50\% maximal voluntary isometric contraction (MVIC)) using three types of pinches (tip pinch, palmar pinch, and key pinch) and to reproduce these forces using the same hand. The subjects were tested twice by the same experienced testers, 1 week apart.

Results: Based on the high values of the intraclass correlation coefficient (ICC), the tip pinch (0.783-0.895) and palmar pinch (0.752-0.903) force sense tests demonstrated good reliability for all the variables. The ICCs for the key pinch (0.712-0.881) indicated fair to good relative test-retest reliability.

Conclusion: 1) This study demonstrates that high test-retest reliability of tip, key, and palmar pinch force sense in healthy adults can be achieved using standardized positioning and the proposed approach. 2) According to the reliability measurements, 30 and 50\% maximal voluntary isometric contraction (MVIC) are the most reliable pinch force sense levels.
\end{abstract}

Keywords: Proprioception, Force sense, Tip pinch, Key pinch, Palmar pinch, Test-retest reliability

\section{Background}

Proprioception is critical for accurate movement. It enables communication from the periphery to the central nervous system (CNS), which is required for the body to acquire joint position awareness and maintain a desired postural orientation and overall position in space. There are three types of conscious proprioceptive senses: kinesthesia, joint position sense, and force sense [1, 2]. All of them, especially force sense, play a role in good neuromuscular control. Force sense is defined as the ability to detect and in-

\footnotetext{
* Correspondence: Imm333_0@163.com

${ }^{2}$ College of Physical Education, Langfang Teachers University, Langfang, Hebei 065000, People's Republic of China

Full list of author information is available at the end of the article
}

terpret forces applied to or generated within a joint [3]. Force sense is measured by the performance accuracy of individuals during force reproduction tasks, which are defined as tasks in which individuals are instructed to produce target forces and reproduce these forces [4].

Different types of pinch grips (tip pinch, palmar pinch, key pinch [5-9]) or combinations of these pinch grips with different force levels are frequently used in workplaces. Workers in various occupations, such as mechanics, repair persons, and engineers, must maintain various pinch grips at constant, submaximum force levels using various hand tools and equipment when performing a wide range of operations, from the assembly of small electronic parts to the assembly of large airplanes. Spontaneously pinching an object is a complex motor task since a

(c) The Author(s). 2020 Open Access This article is licensed under a Creative Commons Attribution 4.0 International License, which permits use, sharing, adaptation, distribution and reproduction in any medium or format, as long as you give appropriate credit to the original author(s) and the source, provide a link to the Creative Commons licence, and indicate if changes were made. The images or other third party material in this article are included in the article's Creative Commons licence, unless indicated otherwise in a credit line to the material. If material is not included in the article's Creative Commons licence and your intended use is not permitted by statutory regulation or exceeds the permitted use, you will need to obtain permission directly from the copyright holder. To view a copy of this licence, visit http://creativecommons.org/licenses/by/4.0/. The Creative Commons Public Domain Dedication waiver (http://creativecommons.org/publicdomain/zero/1.0/) applies to the data made available in this article, unless otherwise stated in a credit line to the data. 
sufficient pinch force must be applied to prevent slipping and, at the same time, excessive force must be avoided to prevent the object from being crushed or the person from experiencing unnecessary fatigue. Repeated and unnecessarily high pinch forces have been previously identified as risk factors for the development of musculoskeletal disorders (MSDs), including carpal tunnel syndrome (CTS) [10, 11], tendonitis [12], and epicondylitis [13].

Test-retest reliability is clinically important for the accurate interpretation of follow-up results. If a measurement procedure or tool has good test-retest reliability, accurate comparisons can be made over time intervals. Reliable test results allow clinicians to draw conclusions that are minimally affected by external factors, thereby reducing the chances of error. Previous studies have investigated the test-retest reliability of the force sense test in ankles [14], knees [15], hips [16], shoulders [17], and hand grips [18]. To the best of our knowledge, no previous studies have investigated the reliability of the pinch force sense test. Compared with other segments in the human body, the finger has few muscles and is easily fatigued. In addition, the sensing and control of forces are complicated by the coordination of the two or three fingers (thumb, index, and long finger) that are involved in the pinch grip. Therefore, the objective of this study was to investigate the testretest reliability of the pinch force sense test in healthy adults.

\section{Methods}

\section{Participants}

Fifty-six healthy subjects (31 women and 25 men, age $21.7 \pm 5.9$ years, weight $62.6 \pm 12.7 \mathrm{~kg}$, height $168.4 \pm 8.1 \mathrm{~cm}$, all right-handed) were tested. The sample size was based on the recommendations of Fleiss, who indicated that 15 to 20 subjects are sufficient for estimating the reliability of a quantitative variable [19]. Hand dominance was indicated by the subjects based on the hand used for writing. The exclusion criteria included 1) a long-standing history of highly skilled motor activity, such as playing a musical instrument or basketball [20], 2) a prior hand surgery, and 3) the presence of hand pain or a hand pathology. The objectives of the study and the experimental procedure were carefully explained to the subjects, and written consent forms were obtained [21]. Authorization to carry out this research was granted by our university's ethics review board.

\section{Apparatus}

Strength tests and force reproduction estimations were conducted using an electronic digital force dynamometer (pinch analyzer; Kjyl Technologies, $\mathrm{CHN}$ ). Calibration of the instrument was performed by the manufacturer. Preliminary testing was also performed to prevent errors during the study. The pinch span of the dynamometer was adjustable and was set at $2 \mathrm{~cm}$ in the strength tests and force reproduction estimations. For the present study, the sampling frequency was fixed at $100 \mathrm{~Hz}$. Based on the pinch analyzer, a protocol in which the pinch force sense is measured was developed.

\section{Protocol}

The study was performed in a quiet room to ensure that auditory distractions were properly minimized [22]. The subjects sat in a chair that was located approximately $60 \mathrm{~cm}$ from a 14-in. LCD monitor, and they assumed a whole-body posture that was in line with the American Society of Hand Therapists guidelines: the upper arm was positioned vertically, the elbow was flexed at $90^{\circ}$, and the forearm and wrist were set in neutral positions [23] (Fig. 1a). The subjects performed isometric pinching tasks with three types of pinches: the tip pinch, palmar pinch, and key pinch. For the tip pinch, the tip of the thumb touched the index fingertip while the other fingers are fully flexed (Fig. 1b). For the palmar pinch, the pad of the thumb touched the pads of the index and long fingers (Fig. 1c). For the key pinch, the pad of the thumb touched the lateral aspect of middle phalanx of the index finger (Fig. 1d) $[5,24]$. The participants were asked to maintain this same arm configuration throughout the testing period. They were able to view their pinch force output on a 14-in. monitor. A PC desktop equipped with a customized MVIC testing program and force reproduction task program (Kjyl Technologies, $\mathrm{CHN}$ ) was used for data acquisition and processing.

\section{MVIC test}

The subjects were instructed to use three different types of pinches (tip, palmar, and key pinch). The types of pinches were presented in a random order. They performed warm-up activities for the type of pinch force that was tested first. The warm-up activities consisted of three repetitions of achieving a submaximal pinch grip force, as measured by the dynamometer [25]: The subjects were instructed to apply a maximal pinch force on the dynamometer after the warm-up activities. This test was repeated twice for each type of pinch grip, and the highest value was recorded as the pinch strength [26]. To minimize the effect of fatigue, three-minute resting periods were allowed between tests. 


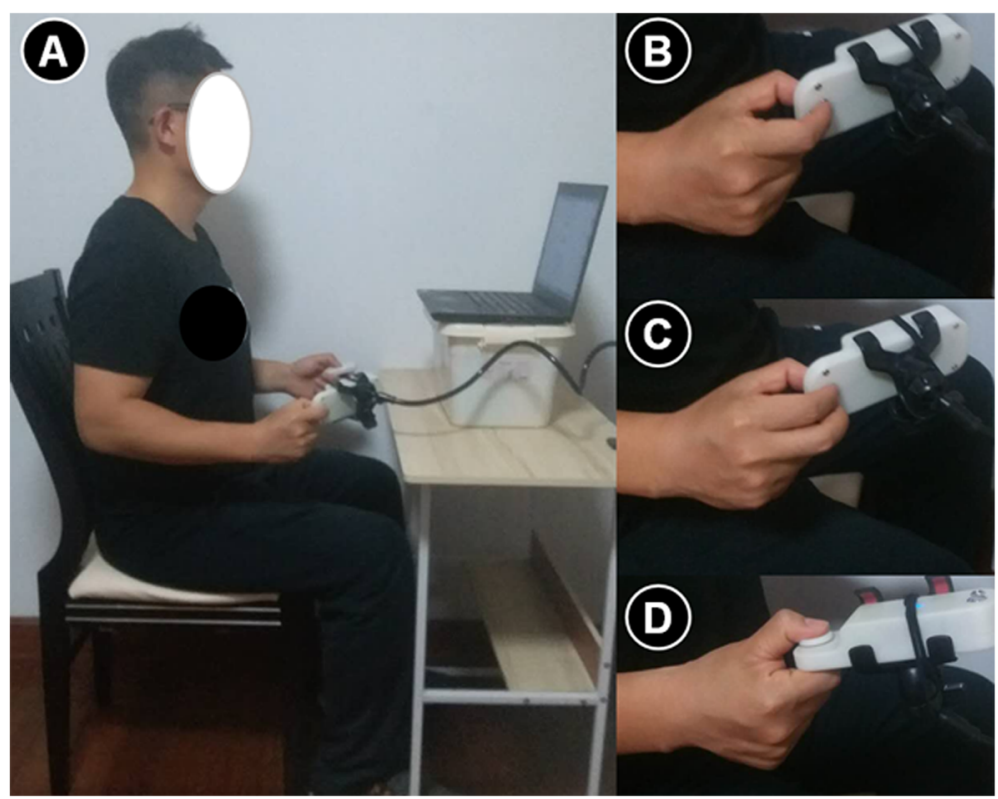

Fig. 1 The standardized positioning (a) used for tip (b), palmar (c), and key pinch (d) force sense measurement

\section{Force reproduction task}

Force sense was measured by the accuracy of the subjects in the reproduction of force tasks. The subjects were informed on how to perform the test as they watched a visual demonstration on a computer monitor. A screen with a black circle was shown to the subjects using proprietary $\mathrm{C}++$ software. The black circle signified the target force for a given trial. A gray dot then appeared on the screen, indicating the instantaneous pinch force (Fig. 2). The subjects were required to apply a target force $T$ with a pinch grip for $3 \mathrm{~s}$, and they were asked to remember the applied
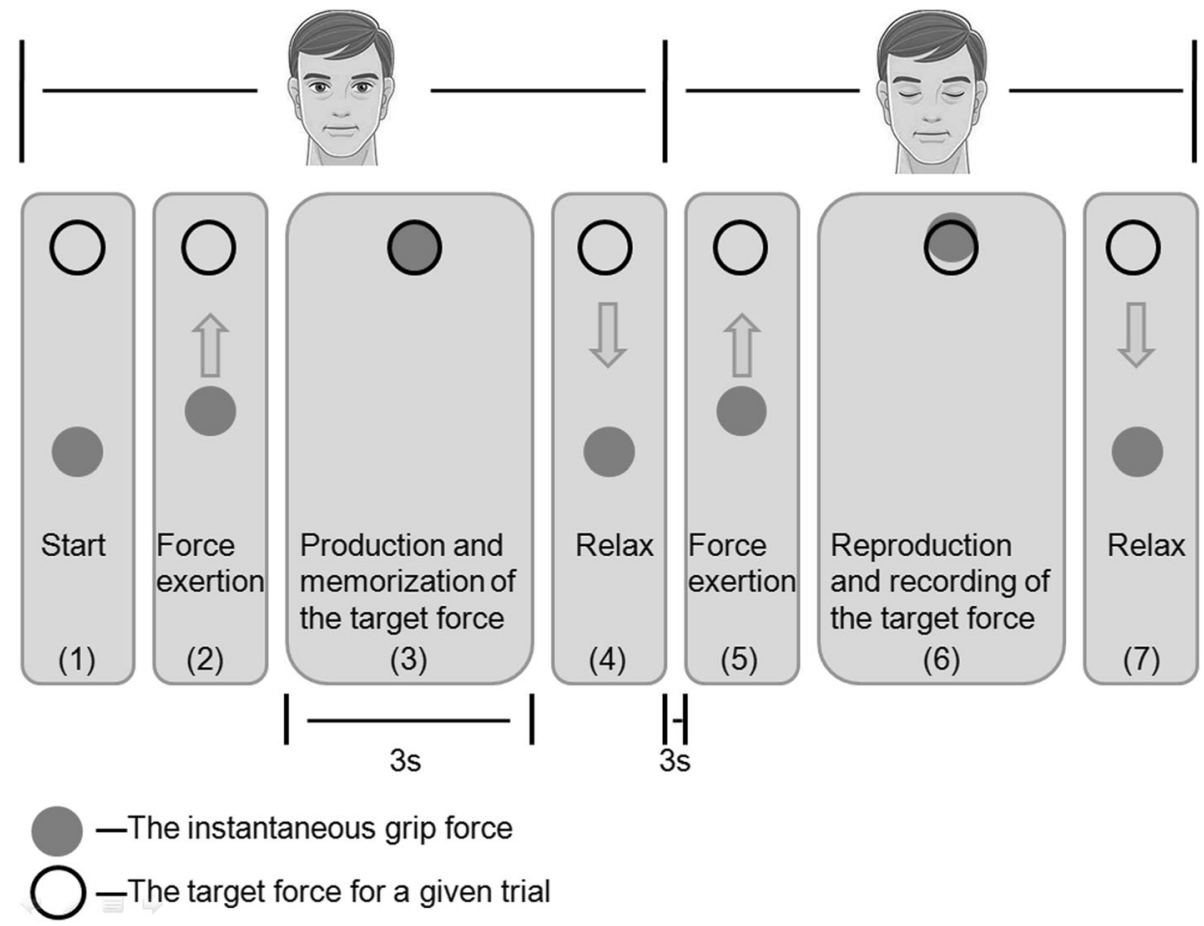

Fig. 2 Schematic of the computer output displayed on the monitor to guide the subject to the target force 
force. They were then given a verbal cue to relax and close their eyes. After a duration of $3 \mathrm{~s}$, the subjects were required to replicate the previous force using the same fingers without any visual feedback. When they believed that the force level was equivalent to the previous one, the subjects pressed a trigger using the other hand, and the computer recorded the force exerted $(R)$. The subject was again requested to relax. The subjects performed a standardized warm-up that consisted of three repetitions of the test procedure for familiarization with the apparatus and estimation process and to promote relaxation. Three different types of pinches (tip, palmar, and key pinch) and forces $(10,30$, and $50 \%$ MVIC) were replicated by the subject, and three contractions were reproduced at each force level. The target forces were presented in a random order. To avoid fatigue, there was a 30$s$ rest period at the end of each trial, and the subjects were allowed to rest for 2 to $3 \mathrm{~min}$ after each set of 5 trials to promote attentiveness during the tasks [27]. Each subject performed 9 trials on two occasions (session 1 and session 2), which took place at approximately the same time of day 1 week apart, with the same experienced tester in the same laboratory to evaluate the reliability and measurement precision of the pinch force sense [27, 28]. The trials were repeated in a randomized order that differed from that used for the first sequence of 9 trials. The participants self-reported that they did not develop any health-related/clinical/functional modifications between the test and the retest. In addition, the participants were instructed to avoid participation in physical activity immediately before the test session and between the test and the retest to prevent fatigue from influencing the testing.

\section{Data analysis}

There were two dependent variables for the force sense errors: absolute error (AE) [29-35] and constant error (CE) [36-40]. AE is an assessment of the overall error, and $C E$ reflects the directionality of the errors (overshoot or undershoot). These parameters were calculated using the following equations:

$$
\begin{aligned}
& A E=\frac{\sum_{i=1}^{3}\left|R_{i}-T\right|}{3 \cdot T} \times 100 \%,(i=1,2,3), \\
& C E=\frac{\sum_{i=1}^{3}\left(R_{i}-T\right)}{3 \cdot T} \times 100 \%,(i=1,2,3),
\end{aligned}
$$

where $R_{i}$ is the reproduction force for the $i$ th trial and $T$ is the target position.

Prior to the analysis, the data were tested for normal distributions using the Kolmogorov-Smirnov test. In the literature, there are contradictory opinions on the best method to calculate reliability or measurement error [41], and it has been stated that a single analysis is inadequate [42, 43]. Therefore, numerous statistical methods were used to determine test-retest reliability: 1) mean difference with a 95\% confidence interval (CI) [28] and 2) intraclass correlation coefficient (ICC) [44] with $95 \%$ CI [45] estimates were performed based on 2-way mixed effects, absolute-agreement, and single-measurement models [46]. The criteria used to assess and accept the ICC values were as follows: poor -0.00 to 0.39 ; fair 0.40 to 0.74 ; and good -0.75 to 1.00 [47]. To assess the systematic differences between the two sessions, a paired $t$-test was performed [48]. 3) The standard error of the measurement (SEM) formula was used to determine the absolute index of reliability [43]. SEM is expressed in actual units and is not influenced by between-subject variability. A high SEM indicates a high level of error, which is indicative of the nonreproducibility of the tested values. 4) The Bland and Altman method of assessing agreement for individual subjects was used; a scatterplot of the differences between session 1 and session 2 (session 2 - session 1) plotted against their mean with 95\% limits of agreement $(\mathrm{LOA}) \quad(\mathrm{LOA}=$ mean difference $\pm 1.96 \mathrm{SD})$ was created [49]. If the $95 \%$ confidence interval (CI) included the value " 0 ", then there was no significant variation in the mean $[28,50]$. Statistical analyses were performed using SPSS 22.0 (SPSS Inc.). All data are represented as the mean $\pm \mathrm{SD}$, and $P<0.05$ was considered to be statistically significant.

\section{Results}

Tables 1, 2 and 3 show the mean $\mathrm{AE}$ and $\mathrm{CE}$ and mean difference with $95 \% \mathrm{CI}$ in relation to the reliability statistics, including the ICC with $95 \% \mathrm{CI}$, SEM, and 95\% LOA between the test and retest for the three types of pinches at three force levels. The ICCs of $\mathrm{AE}$ and $\mathrm{CE}$ for the tip pinch (0.783 to 0.895) and palmar pinch (0.752 to 0.903$)$ indicate good relative test-retest reliability. The ICCs of AE and CE for the key pinch ranged from 0.712 to 0.881 , indicating fair to good relative test-retest reliability. The SEMs at 30 and 50\% MVIC were lower than that at 10\% MVIC.

The Bland-Altman plots are presented in Figs. 3, 4 and 5 . The 30 and 50\% MVIC results showed a narrow 95\% LOA.

\section{Discussion}

\section{Test-retest reliability}

Previous studies have determined that the ICC of the hand grip force sense is moderately reliable (ICC $=$ 0.704) [18]. Benjaminse claimed that good intersession reliability $(\mathrm{ICC}=0.764)$ of the force sense in the hip joint was observed during flexion. $\mathrm{He}$ also claimed 
Table 1 Test-retest reliability results of the tip pinch force sense

\begin{tabular}{llllllll}
\hline & Force level & Session 1 (\%) & Session 2 (\%) & Mean difference (\%) & ICC (95\% CI) & SEM (\%) & 95\% LOA (\%) \\
\hline $\mathrm{AE}$ & $10 \% \mathrm{MVIC}$ & $47.4 \pm 33.4$ & $44.3 \pm 27.8$ & $3.1 \pm 19.9$ & $0.88(0.80-0.93)$ & 6.86 & $-36.0-42.2$ \\
& 30\% MVIC & $13.7 \pm 8.3$ & $14.5 \pm 8.1$ & $-0.8 \pm 6.9$ & $0.78(0.63-0.87)$ & 3.23 & $-14.4-12.7$ \\
& $50 \% \mathrm{MVIC}$ & $14.3 \pm 8.1$ & $13.1 \pm 7.6$ & $1.2 \pm 6.6$ & $0.78(0.63-0.87)$ & 3.07 & $-11.8-14.2$ \\
$\mathrm{CE}$ & $10 \% \mathrm{MVIC}$ & $43.6 \pm 37.4$ & $41.3 \pm 31.3$ & $2.4 \pm 21.4$ & $0.90(0.82-0.94)$ & 6.94 & $-39.5-44.3$ \\
& $30 \% \mathrm{MVIC}$ & $4.5 \pm 14.6$ & $4.6 \pm 14.7$ & $0.0 \pm 9.6$ & $0.88(0.80-0.93)$ & 3.33 & $-18.9-18.8$ \\
& $50 \% \mathrm{MVIC}$ & $-7.3 \pm 13.3$ & $-7.5 \pm 11.3$ & $0.2 \pm 8.6$ & $0.86(0.77-0.92)$ & 3.19 & $-16.7-17.1$ \\
\hline
\end{tabular}

Mean absolute error (AE), constant error (CE), mean difference, intraclass correlation coefficient (ICC) with $95 \%$ confidence interval (CI), standard error of the measurement (SEM), and $95 \%$ limits of agreement (LOA) between the test and retest of the tip pinch at three force levels

that the force sense in the hip in other planes were not reliable [16]. In the shoulders, the force sense measurement is very reliable (internal rotation: $\mathrm{ICC}=$ 0.981, external rotation: $\mathrm{ICC}=0.978$ ) [17]. Based on a literature survey, it was determined that the reliability of the pinch force sense has not been investigated. The acquired results indicated that the test-retest reliability of the pinch force sense in healthy subjects can generate stable and similar measurements at three force levels (10, 30, and 50\% MVIC). Therefore, in this study, moderate reliability of the pinch force sense was determined to be acceptable.

Based on the high value of the ICC results in our study, the tip pinch and palmar pinch force sense test demonstrated good reliability, and the key pinch indicate fair to good reliability. To assess the measurement error magnitude, absolute reliability or agreement was considered [51]. SEM facilitates the quantification of absolute reliability and can be reported in the actual units of measurement. The SEMs at 30 and 50\% MVIC were lower than that at $10 \%$ MVIC. The Bland-Altman plot analysis shows that the $95 \%$ CI includes the value zero. This result indicates that there was no statistically significant difference between test and retest. One value (1.8\%) were outside the range of the $95 \%$ LOA range, as shown in Fig. 3 (E) and Fig. 4b. Two values (3.6\%) were outside the range of the $95 \%$ LOA range, as shown in Fig. 4a, d and Fig. 5f. Three (5.4\%) were outside the range of the $95 \%$ LOA, as shown in
Fig. 3f, Fig. 4e, f, and Fig. 5e. Four (7.1\%) were outside the range of the $95 \%$ LOA, as shown in Fig. 3a, b, c, d and Fig. 5b, c, d. Five (8.9\%) were outside the range of the 95\% LOA, as shown in Fig. 4c, and Fig. 5a. The mean difference was near zero, which indicates fair reproducibility.

The ranges of the 95\% LOA for the 30 and 50\% MVIC variables were narrower than those of the 10\% MVIC variables. The SEM values and Bland-Altman plot revealed that the agreement and reproducibility of the 30 and 50\% MVIC conditions were superior to those observed at $10 \%$ MVIC.

\section{Factors affecting reliability}

Reliability can be affected by the experimental conditions and other variables that vary between the initial test and the retest. These variables include the effects of fatigue, learning, and memory on performance. To minimize the potential for any fatigue effects due to difficulties in concentrating, the subjects were allowed to rest for $30 \mathrm{~s}$ at the end of each trial and for 2 to 3 min after 5 trials [27]. The small improvement in the $\mathrm{AE}$ and $\mathrm{CE}$ in the second measurement may be indicative of an overall learning effect. The force reproduction task was practiced repeatedly until subjects reported that they were comfortable performing these estimates and that they understood all the instructions. This practice helped the participants understand the testing procedure and helped reduce the risk of a learning effect. Familiarization processes

Table 2 Test-retest reliability results of the key pinch force sense

\begin{tabular}{llllllll}
\hline & Force level & Session 1 (\%) & Session 2 (\%) & Mean difference (\%) & ICC (95\% CI) & SEM (\%) & 95\% LOA (\%) \\
\hline AE & $10 \% \mathrm{MVIC}$ & $37.4 \pm 29.9$ & $42.1 \pm 32.3$ & $-4.6 \pm 20.5$ & $0.88(0.79-0.93)$ & 7.24 & $-44.8-35.5$ \\
& 30\% MVIC & $14.9 \pm 8.3$ & $13.7 \pm 7.4$ & $1.1 \pm 7.4$ & $0.71(0.51-0.83)$ & 3.99 & $-13.4-15.7$ \\
& $50 \% \mathrm{MVIC}$ & $14.7 \pm 9.9$ & $14.1 \pm 7.9$ & $0.5 \pm 6.3$ & $0.86(0.76-0.92)$ & 2.33 & $-11.7-12.8$ \\
$\mathrm{CE}$ & $10 \% \mathrm{MVIC}$ & $34.0 \pm 32.8$ & $38.2 \pm 35.7$ & $-4.1 \pm 22.2$ & $0.88(0.8-0.93)$ & 7.68 & $-47.7-39.5$ \\
& $30 \% \mathrm{MVIC}$ & $1.9 \pm 16.1$ & $1.9 \pm 14.3$ & $0.1 \pm 10.6$ & $0.86(0.77-0.92)$ & 3.90 & $-20.7-20.8$ \\
& $50 \% \mathrm{MVIC}$ & $-11.9 \pm 12.4$ & $-10.8 \pm 11.1$ & $-1.1 \pm 7.8$ & $0.88(0.79-0.93)$ & 2.72 & $-16.3-14.1$ \\
\hline
\end{tabular}

Mean absolute error (AE), constant error (CE), mean difference, intraclass correlation coefficient (ICC) with $95 \%$ confidence interval (CI), standard error of the measurement (SEM), and $95 \%$ limits of agreement (LOA) between the test and retest of the key pinch at three force levels 
Table 3 Test-retest reliability results of the palmar pinch force sense

\begin{tabular}{llllllll}
\hline & Force level & Session 1 (\%) & Session 2 (\%) & Mean difference (\%) & ICC (95\% Cl) & SEM (\%) & 95\% LOA (\%) \\
\hline AE & $10 \%$ MVIC & $39.8 \pm 34.5$ & $43.5 \pm 32.4$ & $-3.7 \pm 26.8$ & $0.81(0.68-0.89)$ & 11.69 & $-56.2-48.9$ \\
& $30 \%$ MVIC & $12.4 \pm 7.7$ & $13.8 \pm 10.4$ & $-1.4 \pm 8.2$ & $0.75(0.58-0.85)$ & 4.06 & $-17.4-14.6$ \\
& $50 \% \mathrm{MVIC}$ & $16.0 \pm 9.1$ & $14.3 \pm 9.2$ & $1.6 \pm 6.5$ & $0.85(0.74-0.91)$ & 2.55 & $-11.2-14.5$ \\
CE & $10 \% \mathrm{MVIC}$ & $35.0 \pm 39.1$ & $37.7 \pm 38.2$ & $-2.7 \pm 28.5$ & $0.84(0.73-0.91)$ & 11.29 & $-58.6-53.3$ \\
& 30\% MVIC & $2.4 \pm 12.8$ & $0.0 \pm 15.9$ & $2.4 \pm 10.3$ & $0.85(0.74-0.91)$ & 4.01 & $-17.8-22.7$ \\
& 50\% MVIC & $-10.6 \pm 13.8$ & $-10.4 \pm 12.3$ & $-0.2 \pm 7.8$ & $0.90(0.83-0.94)$ & 2.43 & $-15.5-15.2$ \\
\hline
\end{tabular}

Mean absolute error (AE), constant error (CE), mean difference, intraclass correlation coefficient (ICC) with $95 \%$ confidence interval (CI), standard error of the measurement (SEM), and $95 \%$ limits of agreement (LOA) between the test and retest of the palmar pinch at three force levels
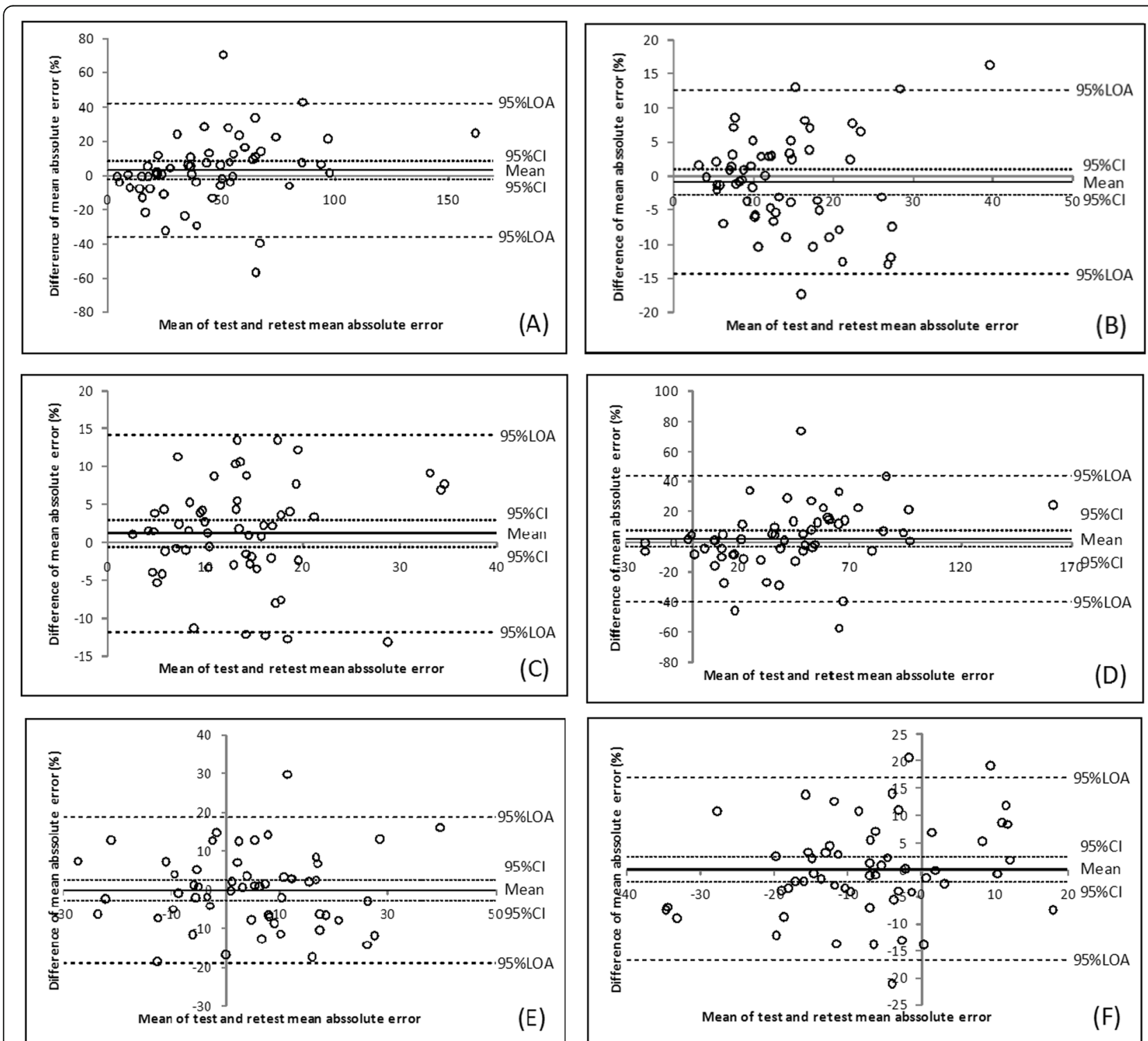

Fig. 3 Bland-Altman plots for the AE at 10\% MVIC (a), 30\% MVIC (b), and 50\% MVIC (c) and for the CE at 10\% MVIC (d), 30\% MVIC (e), and 50\% MVIC (f) of the tip pinch 

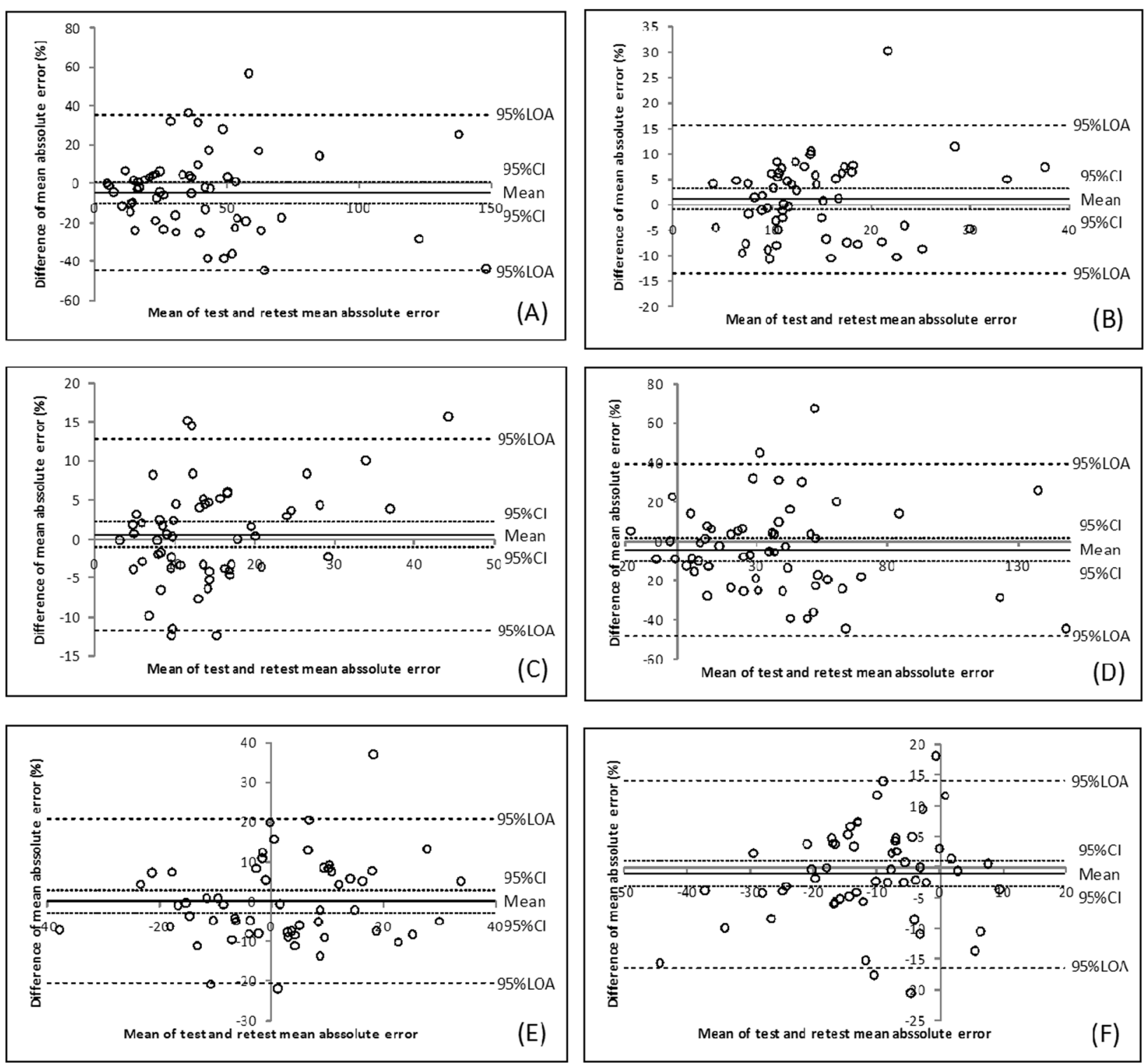

Fig. 4 Bland-Altman plots for the AE at 10\% MVIC (a), 30\% MVIC (b), and 50\% MVIC (c) and for the CE at 10\% MVIC (d), 30\% MVIC (e), and 50\% MVIC (f) of the key pinch

also have the potential to improve test reproducibility [52-55]. The order of the target forces was also randomized to avoid any learning effects associated with the limited test-retest time difference. To minimize the influence of learning or fatigue on the reproducibility of the study, the test and retest reliability sessions were separated by a period of 7 days. It has been confirmed in previous studies that longer intervals of 1-7 days between sessions can improve testretest reliability $[16,28,56]$. The measurement of proprioception via pinch force sense ipsilateral testing is reliant upon the ability of the subjects to replicate the target force levels from memory [57, 58]. To minimize the potential for any memory effects due to difficulties in concentrating, the study was performed in a quiet room.

\section{Limitations}

In this study, standardization of the pinch force sense procedure reduced the potential for differences in the conditions for the test and retest measurements. A high reliability was observed for the pinch force sense measurements in healthy adults. However, our study has some limitations. For example, the small sample size is insufficient to represent the population. In addition, only healthy young adults with a mean age of 18.6 years were 

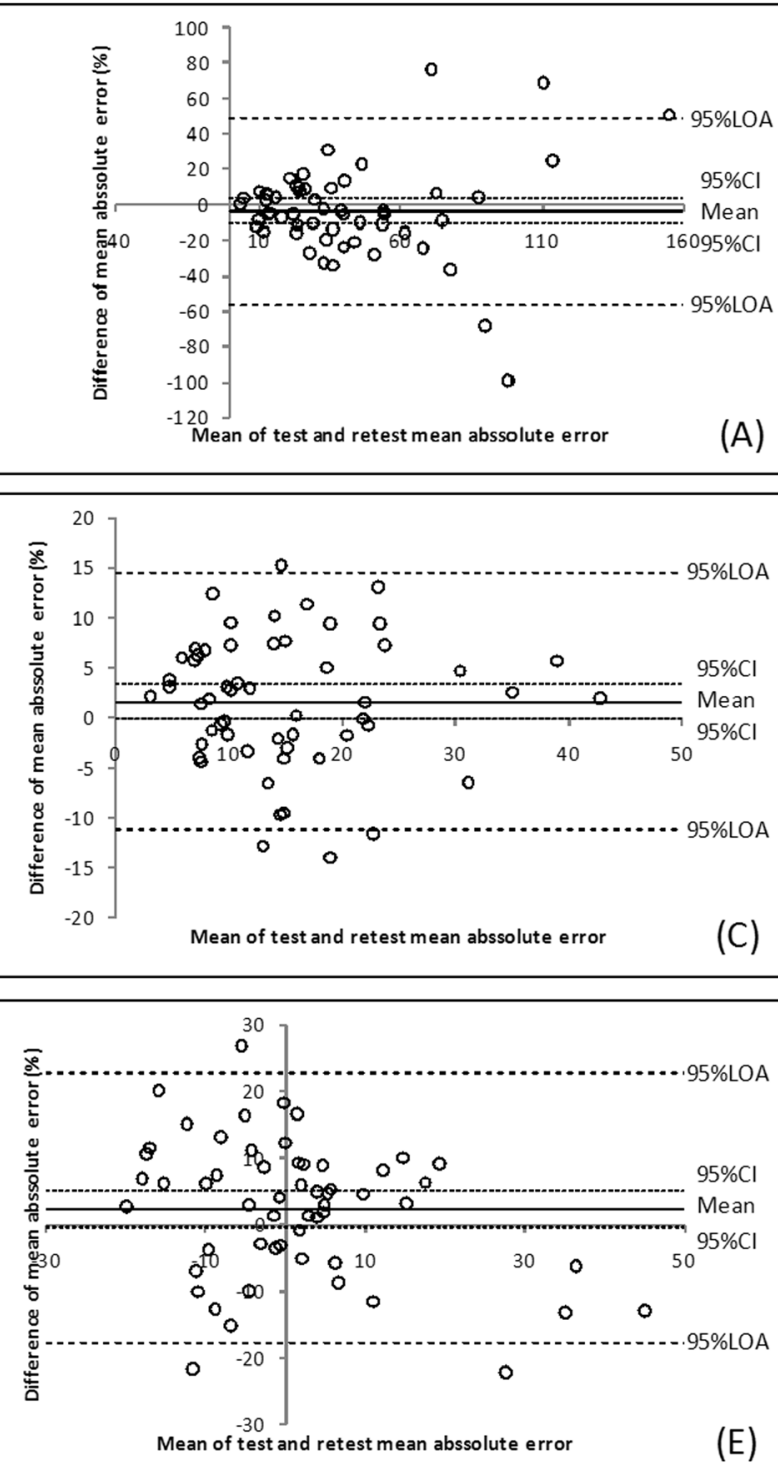

(E)
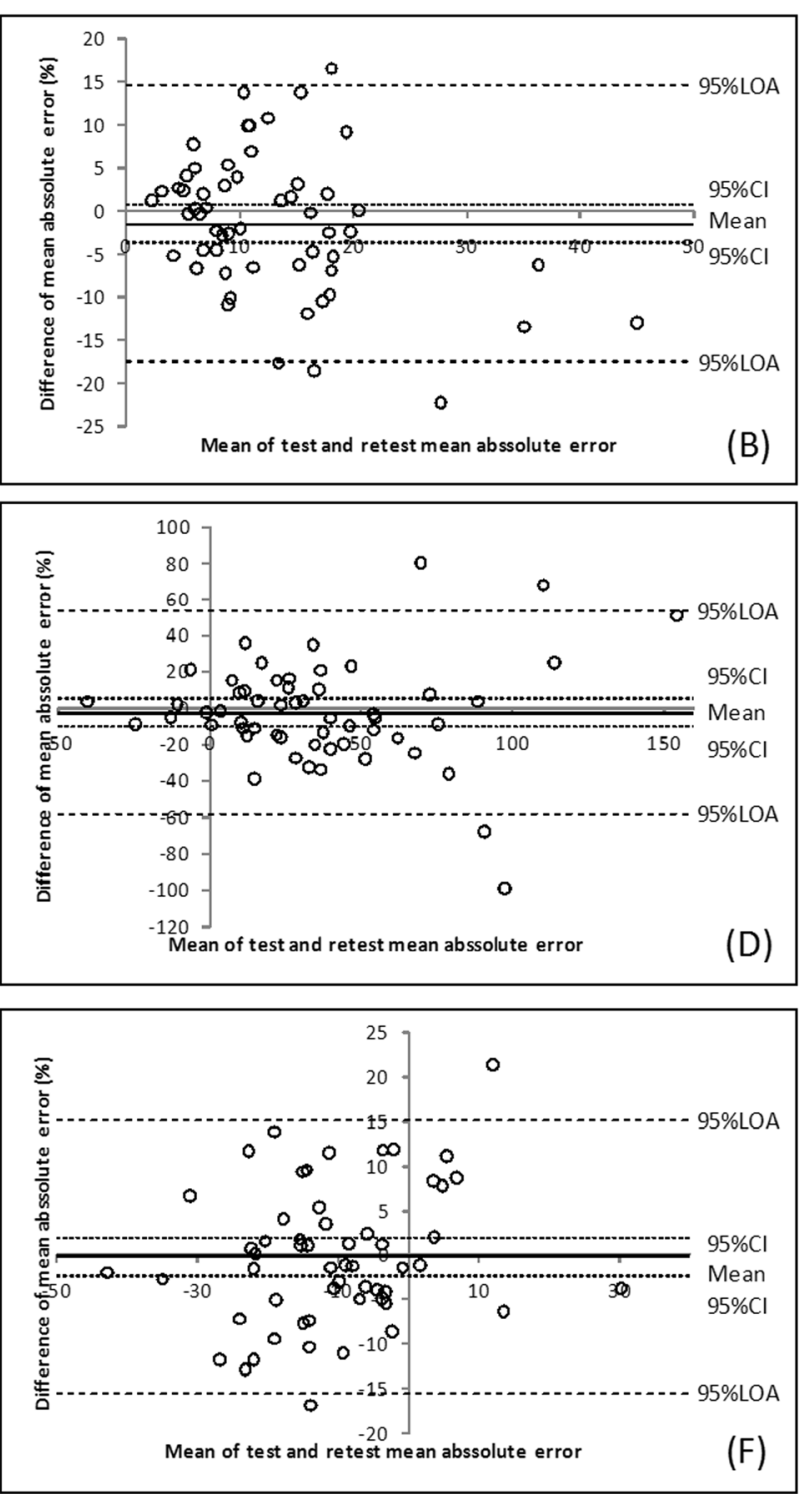

Fig. 5 Bland-Altman plots for the AE at 10\% MVIC (a), 30\% MVIC (b), and 50\% MVIC (c) and for the CE at 10\% MVIC (d), 30\% MVIC (e), and 50\% MVIC (f) of the palmar pinch

enrolled in this study. Therefore, the excellent testretest reliability in the study may only be valid for the assessment of pinch force sense in similarly aged and healthy individuals. Thus, additional studies are needed to examine these relationships among other age groups.

\section{Conclusion}

The results confirm the fair to good reliability of the force reproduction test for measuring pinch force sense in healthy adults. The lower SEM values and the narrower 95\% LOA in the $\mathrm{AE}$ and $\mathrm{CE}$ variables obtained for 30 and 50\% MVIC compared with 10\%
MVIC indicate that they are more reliable. Based on the satisfactory reliability findings, we draw the following conclusions: 1) this study demonstrates that high test-retest reliability can be achieved using the standardized positioning and approach that is proposed. 2) According to the reliability of the measurements, 30 and 50\% MVIC are the most reliable pinch force sense levels. Therefore, we recommend that the $\mathrm{AE}$ and $\mathrm{CE}$ variables at 30 and 50\% MVIC are used in future studies of subjects without pathologies. When these recommendations are followed, this test appears to be a reliable means of assessing pinch force sense in healthy controls. 


\section{Abbreviations}

AE: Absolute error; CE: Constant error; Cl: Confidence interval; CNS: Central nervous system; CTS: Carpal tunnel syndrome; ICC: Intraclass correlation coefficient; LOA: Limits of agreement; MSDs: Musculoskeletal disorders; MVIC: Maximal voluntary isometric contraction; SEM: Standard error of the measurement

\section{Acknowledgements}

We would like to show our gratitude to the participants who made this study possible.

\section{Authors' contributions}

$\mathrm{LL}, \mathrm{YXL}, \mathrm{CHW}$ and $\mathrm{XYZ}$ all participated in conception and design of the project and in interpretation of the data. $\mathrm{LL}$ performed the analysis and wrote the initial draft of the manuscript. All authors were involved in the revision of the manuscript, and all read and approved the final manuscript.

\section{Funding}

This research was funded by the Fundamental Research Funds for the Central Universities, and the Research Funds of Renmin University of China (Grant No. 17XNF029). The funding body had no role in the design of the study, collection, analysis, or interpretation of data or in writing the manuscript.

\section{Availability of data and materials}

Raw material can be provided upon request, please contact LL or YXL.

\section{Ethics approval and consent to participate}

The objective of the study and the experimental procedure was explained to the subjects and written consent forms were obtained. The study has been approved by the Ethical Review Board of Renmin University of China (ref. no. 2018007).

\section{Consent for publication}

All study participants gave consent for their identifying image in Fig. 1 to be published in this study.

\section{Competing interests}

The authors declare that they have no competing interests.

\section{Author details}

'Department of Physical Education, Renmin University of China, Beijing, People's Republic of China. ${ }^{2}$ College of Physical Education, Langfang Teachers University, Langfang, Hebei 065000, People's Republic of China. ${ }^{3}$ School of Sociology and Population Studies, Renmin University of China, Beijing, People's Republic of China.

\section{Received: 24 May 2019 Accepted: 3 March 2020}

Published online: 26 March 2020

\section{References}

1. Riemann BL, Lephart SM. The sensorimotor syste $m$, part l: the physiologic basis of functional joint stability. J Athl Train. 2002;37(1):71-9.

2. Cappello L, Contu S, Elangovan N, Khosravani S, Konczak J, Masia L. Evaluation of wrist joint proprioception by means of a robotic device. In: International Conference on Ubiquitous Robots and Ambient Intelligence, vol. 1997; 1997. p. 531-4.

3. Myers JB, Lephart SM. The role of the sensorimotor system in the athletic shoulder. J Athl Train. 2000;35(3):351-63.

4. Park WH, Leonard CT, Li S. Finger force perception during ipsilateral and contralateral force matching tasks. Exp Brain Res. 2008;189(3):301-10.

5. Mathiowetz V, Weber K, Volland G, Kashman N. Reliability and validity of grip and pinch strength evaluations. J Hand Surg. 1984;9(2):222-6.

6. Mathiowetz V, Kashman N, Volland G, Weber K, Dowe M, Rogers S. Grip and pinch strength: normative data for adults. Arch Phys Med Rehabil. 1985; 66(2):69-74

7. Romero-Guzman AK, Menchaca-Tapia VM, Contreras-Yanez I, Pascual-Ramos $\checkmark$. Patient and physician perspectives of hand function in a cohort of rheumatoid arthritis patients: the impact of disease activity. BMC Musculoskelet Disord. 2016;17:392.
8. Puh U. Age-related and sex-related differences in hand and pinch grip strength in adults. Int J Rehabil Res. 2010;33(1):4-11.

9. Tajika T, Kobayashi T, Yamamoto A, Shitara H, Ichinose T, Shimoyama D, Okura C, Kanazawa S, Nagai A, Takagishi K. Relationship between grip, pinch strengths and anthropometric variables, types of pitch throwing among Japanese high school baseball pitchers. Asian J Sports Med. 2015;6(1): e25330.

10. Birkbeck MQ, Beer TC. Occupation in relation to the carpal tunnel syndrome. Rheumatol Rehabil. 1975;14(4):218-21.

11. Silverstein BA, Fine $\amalg$, Armstrong TJ. Occupational factors and carpal tunnel syndrome. Am J Ind Med. 1987;11(3):343-58.

12. Silverstein BA, Fine $\sqcup$, Armstrong TJ. Hand wrist cumulative trauma disorders in industry. Br J Ind Med. 1986:43(11):779-84.

13. Feldman RG, Goldman R, Keyserling WM. Classical syndromes in occupational medicine. Peripheral nerve entrapment syndromes and ergonomic factors. Am J Ind Med. 1983;4(5):661-81.

14. Zhang QX, Sun PQ. Test-retest reliability of muscle force sense of the ankle joint under different target torque. Chinese J Tissue Eng Res. 2012;16(7):1255-58.

15. Zavieh MK, Amirshakeri B, Rezasoltani A, Talebi GA, Kalantari KK, Nedaey V, Baghban AA. Measurement of force sense reproduction in the knee joint: application of a new dynamometric device. J Phys Ther Sci. 2016;28(8):2311-5.

16. Benjaminse A, Sell TC, Abt JP, House AJ, Lephart SM. Reliability and precision of hip proprioception methods in healthy individuals. Clin J Sport Med. 2009;19(6):457-63.

17. Dover G, Powers ME. Reliability of joint position sense and forcereproduction measures during internal and external rotation of the shoulder. J Athl Train. 2003;38(4):304-10.

18. Chang HY, Chou KY, Lin JJ, Lin CF, Wang CH. Immediate effect of forearm Kinesio taping on maximal grip strength and force sense in healthy collegiate athletes. Phys Ther Sport. 2010;11(4):122-7.

19. Fleiss JL. The design and analysis of clinical experiments. New York: Wiley; 1999.

20. Adamo DE, Alexander NB, Brown SH. The influence of age and physical activity on upper limb proprioceptive ability. J Aging Phys Act. 2009:17(3): 272-93

21. Proske U, Gandevia SC. The proprioceptive senses: their roles in signaling body shape, body position and movement, and muscle force. Physiol Rev. 2012;92(4):1651-97.

22. Lubiatowski P, Ogrodowicz P, Wojtaszek M, Kaniewski R, Stefaniak J, Dudzinski W, Romanowski L. Measurement of active shoulder proprioception: dedicated system and device. Eur J Orthop Surg Traumatol. 2013:23(2):177-83.

23. van den Noort JC, Wiertsema SH, Hekman KM, Schonhuth CP, Dekker J, Harlaar J. Reliability and precision of 3D wireless measurement of scapular kinematics. Med Biol Eng Comput. 2014:52(11):921-31.

24. Visser B, Looze MPD, Veeger DJ, Douwes M, Groenesteijn L, Korte ED, Dieën $\mathrm{JHV}$. The effects of precision demands during a low intensity pinching task on muscle activation and load sharing of the fingers. J Electromyogr Kinesiol. 2003:13(2):149-57.

25. Jansen CW, Niebuhr BR, Coussirat DJ, Hawthorne D, Moreno L, Phillip M. Hand force of men and women over 65 years of age as measured by maximum pinch and grip force. J Aging Phys Act. 2008;16(1):24-41.

26. Bao S, Silverstein B. Estimation of hand force in ergonomic job evaluations. Ergonomics. 2005;48(3):288-301.

27. Marini F, Squeri V, Morasso P, Campus C, Konczak J, Masia L. Robot-aided developmental assessment of wrist proprioception in children. J Neuroeng Rehabil. 2017;14(1):3.

28. Ageberg E, Flenhagen J, Ljung J. Test-retest reliability of knee kinesthesia in healthy adults. BMC Musculoskelet Disord. 2007:8:57.

29. Baray AL, Philippot R, Farizon F, Boyer B, Edouard P. French Association of Foot S. assessment of joint position sense deficit, muscular impairment and postural disorder following hemi-Castaing ankle ligamentoplasty. Orthopaed Traumatol Surg Res. 2014;100(6 Suppl):271-4.

30. Bang DH, Shin WS, Choi SJ, Choi HS. Comparison of the effect of weightbearing and non-weight-bearing positions on knee position sense in patients with chronic stroke. J Phys Ther Sci. 2015;27(4):1203-6.

31. Duzgun I, Kanbur NO, Baltaci G, Aydin T. Effect of Tanner stage on proprioception accuracy. J Foot Ankle Surg. 2011:50(1):11-5.

32. Vila-Cha C, Riis S, Lund D, Moller A, Farina D, Falla D. Effect of unaccustomed eccentric exercise on proprioception of the knee in weight and non-weight bearing tasks. J Electromyogr Kinesiol. 2011;21(1):141-7. 
33. Han JT, Lee JH. Effects of kinesiology taping on repositioning error of the knee joint after quadriceps muscle fatigue. J Phys Ther Sci. 2014;26(6):921-3.

34. Trousset K, Phillips D, Karduna A. An investigation into force sense at the shoulder. Mot Control. 2018:22(4):462-71.

35. Maenhout AG, Palmans T, De Muynck M, De Wilde LF, Cools AM. The impact of rotator cuff tendinopathy on proprioception, measuring force sensation. J Shoulder Elbow Surg. 2012;21 (8):1080-6.

36. Knox JJ, Hodges PW. Changes in head and neck position affect elbow joint position sense. Exp Brain Res. 2005;165(1):107-13.

37. Salgado E, Ribeiro F, Oliveira J. Joint-position sense is altered by football pre-participation warm-up exercise and match induced fatigue. Knee. 2015; 22(3):243-8

38. Winter JA, Allen TJ, Proske U. Muscle spindle signals combine with the sense of effort to indicate limb position. J Physiol. 2005;568(Pt 3):1035-46.

39. Bennell K, Wee E, Crossley K, Stillman B, Hodges P. Effects of experimentallyinduced anterior knee pain on knee joint position sense in healthy individuals. J Orthopaed Res. 2005;23(1):46-53.

40. Lonn J, Crenshaw AG, Djupsjobacka M, Pedersen J, Johansson H. Position sense testing: influence of starting position and type of displacement. Arch Phys Med Rehabil. 2000;81(5):592-7.

41. Hopkins WG. Measures of reliability in sports medicine and science. Sports Med. 2000:30(1):1-15.

42. Rankin G, Stokes M. Reliability of assessment tools in rehabilitation: an illustration of appropriate statistical analyses. Clin Rehabil. 1998;12(3):187-99.

43. Weir JP. Quantifying test-retest reliability using the intraclass correlation coefficient and the SEM. J Strength Cond Res. 2005;19(1):231-40.

44. Ellison PH, Sparks SA, Murphy PN, Carnegie E, Marchant DC. Determining eye-hand coordination using the sport vision trainer: an evaluation of testretest reliability. Res Sports Med. 2014;22(1):36-48.

45. Palmer TB, Jenkins ND, Cramer JT. Reliability of manual versus automated techniques for assessing passive stiffness of the posterior muscles of the hip and thigh. J Sports Sci. 2013;31(8):867-77.

46. Koo TK, Li MY. A guideline of selecting and reporting Intraclass correlation coefficients for reliability research. J Chiropr Med. 2016;15(2):155-63.

47. Shrout PE, Fleiss JL. Intraclass correlations: uses in assessing rater reliability. Psychol Bull. 1979;86(2):420-8.

48. Anderson VB, Wee E. Impaired joint proprioception at higher shoulder elevations in chronic rotator cuff pathology. Arch Phys Med Rehabil. 2011; 92(7):1146-51.

49. Aandstad A, Simon EV. Reliability and validity of the soccer specific INTER field test. J Sports Sci. 2013;31(13):1383-92.

50. Pinsault N, Fleury A, Virone G, Bouvier B, Vaillant J, Vuillerme N. Test-retest reliability of cervicocephalic relocation test to neutral head position. Physiother Theory Pract. 2008;24(5):380-91.

51. Pilbeam C, Hood-Moore V. Test-retest reliability of wrist joint position sense in healthy adults in a clinical setting. Hand Ther. 2018;23(3):100-9.

52. Swanik KA, Lephart SM, Swanik CB, Lephart SP, Stone DA, Fu FH. The effects of shoulder plyometric training on proprioception and selected muscle performance characteristics. J Shoulder Elbow Surg. 2002;11(6):579-86.

53. Juul-Kristensen B, Lund H, Hansen K, Christensen H, Danneskiold-Samsoe B, Bliddal $\mathrm{H}$. Test-retest reliability of joint position and kinesthetic sense in the elbow of healthy subjects. Physiother Theory Pract. 2008;24(1):65-72.

54. Goble DJ. Proprioceptive acuity assessment via joint position matching: from basic science to general practice. Phys Ther. 2010;90(8):1176-84.

55. James CR, Herman JA, Dufek JS, Bates BT. Number of trials necessary to achieve performance stability of selected ground reaction force variables during landing. J Sports Sci Med. 2007;6(1):126-34.

56. Holmbäck AM, Porter MM, Downham D, Lexell J. Reliability of isokinetic ankle dorsiflexor strength measurements in healthy young men and women. Scand J Rehabil Med. 1999;31(4):229.

57. Han J, Waddington G, Adams R, Anson J, Liu Y. Assessing proprioception: a critical review of methods. J Sport Health Sci. 2016;5(1):80-90.

58. Goble DJ, Noble BC, Brown SH. Where was my arm again? Memory-based matching of proprioceptive targets is enhanced by increased target presentation time. Neurosci Lett. 2010;481(1):54-8.

\section{Publisher's Note}

Springer Nature remains neutral with regard to jurisdictional claims in published maps and institutional affiliations.

Ready to submit your research? Choose BMC and benefit from:

- fast, convenient online submission

- thorough peer review by experienced researchers in your field

- rapid publication on acceptance

- support for research data, including large and complex data types

- gold Open Access which fosters wider collaboration and increased citations

- maximum visibility for your research: over $100 \mathrm{M}$ website views per year

At $\mathrm{BMC}$, research is always in progress.

Learn more biomedcentral.com/submissions 